\title{
Caracterização Sedimentológica da Planície Intertidal da Parte Sul do Saco do Limoeiro (Ilha do Mel - Paraná - Brasil). I. Implicações Ecológicas
}

\author{
Erminda da Conceição Guerreiro Couto ${ }^{* 1}$ and Michelle Savian ${ }^{2}$ \\ ${ }^{1}$ Departamento de Biologia, Universidade Federal de Sergipe, Campus Universitário, Jardim Rosa Elze, 49100- \\ 000, São Cristóvão, Sergipe. E.mail:minda@sergipe.ufs.br; ${ }^{2}$ Centro de Estudos do Mar, Universidade Federal \\ do Paraná, Av.Beira Mar s/no, Pontal do Sul, CEP 83255-000, Paranaguá - Pr
}

\begin{abstract}
Sediment cores $40 \mathrm{~cm}$ depth were taken in triplicate at nine points along an unvegetable intertidal flat, to assess the ecological implications of sedimentological characteristics. Each core was sectioned in $5 \mathrm{~cm}$ depht layers. In these sub-samples temperature, $p H$, water, organic matter and carbonate content were determined. Granulometric analysis, porosity, qualitative and quantitative identification of sediment components were also carried. The sediments presented low water (15.6 - 37.2 \%), organic matter (0.7 - 5.0 \%) and carbonates (0.3 - $1.0 \%)$ contents, prevailing fine to very fine sand at surface. Statistical analysis showed a strong horizontal homogeneity regarding sedimentological and physiochemical parameters. Organic matter exhibit a general trend of increase with depth, while carbonate content follow an inverse behavior, refleting the higher contribution of bioclastic calcareous. Textural features and qualitative sediment analysis suggest that the biological mechanism of shell crushing is predominant over physical ones in the grinding till sand size. Amongst the involved organisms there is a sponge Clione celata, the mollusks Nassarius vibex and Thais haemastoma floridana (Gastropoda), Martesia striata (Bivalvia), and the spionid polychaete Polydora socialis and P. websteri.
\end{abstract}

Key words: tidal flat, sediments, granulometric analysis, bioclastic calcareous, southeastern Brazil Palavras-chave: planície intertidal, sedimento,análise granulométrica, calcáreo biodetrítico

\section{INTRODUÇÃO}

Planícies de maré são feições comuns de regiões litorâneas, presentes tanto em áreas estuarinas como em costas abrigadas. A forma da costa e o regime de maré determinam a extensão da planície. O ciclo de maré local determina o tempo de exposição da mesma durante a maré baixa. As ondas e as correntes de maré selecionam e redepositam as partículas do sedimento, determinando sua distribuição, estabilidade e composição. Juntamente com o clima local e a geomorfologia, estes fatores compõem a matriz da planície de maré e afetam o padrão de distribuição dos organismos (REISE, 1985). As atividades dos organismos presentes podem modificar, funcionalmente, as características do sedimento (Woodin, 1978).
Este trabalho tem por objetivo a caracterização sedimentológica do banco não vegetado da planície de maré situada na porção sul do Saco do Limoeiro, Ilha do Mel (Baía de Paranaguá Paraná), avaliando as possíveis implicações ecológicas destas características para a macrofauna bêntica presente.

\section{ÁREA DE ESTUDO}

A Ilha do Mel localiza-se na desembocadura do complexo estuarino de Paranaguá (250 20' S $48^{\circ} 20^{\prime} \mathrm{W}$ a $25^{\circ} 35^{\prime} \mathrm{S}-48^{\circ} 35^{\prime} \mathrm{W}$ ) (Fig. 1), estando sob influência oceânica. Informações gerais quanto a hidrologia e características sedimentológicas prevalecentes no Saco do Limoeiro, também denominado "Mar de Dentro", foram apresentadas por diferentes

\footnotetext{
* Autor para correspondência
} 
autores (Bigarella, 1978; Knoppers et al., 1986; Angulo, 1992), referindo-se ao nível inferior da planície intertidal, permanentemente submerso. No nível superior estão localizadas as maiores extensões de manguezal da ilha (Couto et al., 1985).

A planície de maré do Saco do Limoeiro é um ambiente não degradado. O trecho estudado, situado ao sul, apresenta sua parte superior coberta por manguezais pouco desenvolvidos, com dominância do mangue branco (Laguncularia racemosa (L.) Gaertn). Entre o manguezal e o banco não vegetado estão presentes faixas descontínuas da gramínea Spartina alterniflora Loisel. $\mathrm{O}$ trecho considerado tem cerca de $0,3 \mathrm{~km}^{2}(0,4 \mathrm{~km}$ de largura por $0,8 \mathrm{~km}$ de extensão), ficando totalmente exposto durante a maré baixa (Couto et al., 1985).

A maré na região apresenta uma amplitude de sizígia inferior a $2 \mathrm{~m}$, o que caracteriza um regime de micromarés. As diferenças de altitudes entre os níveis máximos e mínimos podem alcançar 2,8 $\mathrm{m}$ em Pontal do Sul (Angulo, 1992).

Durante o período de coleta (Maio e Junho de 1990) o banco encontrava-se quase totalmente recoberto, em sua porção central, por detritos calcáreos provenientes do bivalve Anomalocardia brasiliana e por manchas da rodofícea Acanthophora spicifera e da cianofícea Lyngbya confervoides.

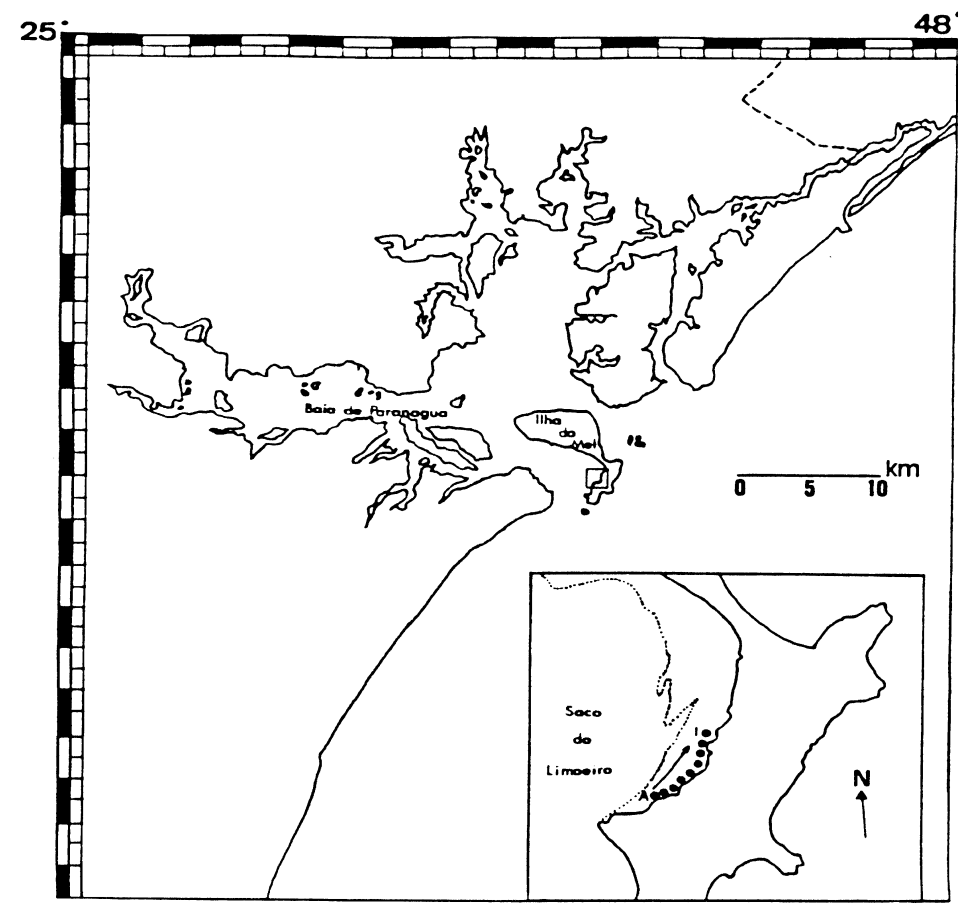

Figura 1. Mapa da área de estudo. Em destaque a distribuição das estações de coleta no limite superior da planície entre marés do Saco do Limoeiro

\section{MATERIAL E MÉTODOS}

O limite inferior médio de exposição do banco, tomando como referência o nível de $+0,1 \mathrm{~m}$ da tábua de maré da DHN para o Canal da Galheta, foi demarcado com estacas fixadas a cada $50 \mathrm{~m}$. A partir desta foram estabelecidas, com auxílio de um sextante, nove linhas, eqüidistantes 100 $\mathrm{m}$, perpendiculares a linha d'água. Em cada uma delas foram tomadas, com um topômetro de campo, as medidas de inclinação a cada $5 \mathrm{~m}$, sendo então traçado o perfil topométrico da área. No limite superior de cada linha foram estabelecidas as estações de coleta (A - I) (Fig. 
1). Foram registradas a temperatura do ar, da água e do sedimento (termômetro de mercúrio, $0,1{ }^{\circ} \mathrm{C}$ de precisão) e tomadas, com testemunhador de PVC $(15 \times 40 \mathrm{~cm})$, três amostras sedimentológicas estratificadas em seções de $5 \mathrm{~cm}$. Em cada estrato foram estimados os teores de matéria orgânica e carbonatos (Dean, 1974), o pH da solução de solo (Couto, 1989), a salinidade da água intersticial (refratômetro ATAGO, precisão de $1 \mathrm{~S}$ ), a composição granulométrica (após lavagem para eliminação dos sais) e a umidade (Suguio, 1973). Foram ainda obtidos três testemunhos igualmente estratificados, testemunhador de PVC 4,5 X $40 \mathrm{~cm}$, para estimativa da porosidade (Berner, 1971). Como complemento à análise granulométrica foi realizada a quantificação e identificação do material disperso na matriz sedimentológica. $\mathrm{O}$ material retido na peneira de malha igual a $1 \mathrm{~mm}$ foi pesado e classificado em função de sua procedência (detrito vegetal, valvas de moluscos - inteiras e fragmentadas, pelotas fecais, tubos, grânulos, grãos de areia grossa, etc). Os dados de análise granulométrica foram processados com o programa LABSE.V02, desenvolvido pelo Dr. Jorge Yamamoto (Lab. de Sedimentologia - Depto de Paleontologia e Estratigrafia - USP / SP). Os dados sedimentológicos e físico - químicos, referentes ao primeiro estrato $(0-5 \mathrm{~cm})$, após padronização $((\mathrm{x}-\mathbf{x}) / \mathrm{s})$ foram ordenados pela análise de componentes principais (DAVIS, 1986), para descrever e sumarizar a variabilidade observada.

Para determinação do grau de associação entre as estações (modo - Q) e entre as variáveis abióticas (modo - R) foram empregadas técnicas de classificação do tipo hierárquico, utilizandose para união entre objetos ou descritores a média aritmética ponderada (WPGMA), aconselhada por respeitar de maneira satisfatória a matriz original de correlação (DAVIS, 1986). A matriz dos dados padronizados $((\mathrm{x}-\mathbf{x}) / \mathrm{s})$ e transformados $(\log x+1)$ foi tratada como quantitativa, adotando-se como medida de dissimilaridade o índice de Bray-Curtis (DAVIS, 1986). Os resultados são apresentados em forma de dendrograma.

\section{RESULTADOS}

Os dados descritivos das estações foram sumarizados na tabela I.

Tabela I. Parâmetros sedimentológicos e físico-químicos obtidos para o primeiro estrato $(0$ - $5 \mathrm{~cm})$ de cada estação.

\begin{tabular}{|c|c|c|c|c|c|c|c|c|c|}
\hline $\begin{array}{ll}\text { ESTAÇÕES } \\
\text { PARÂMETROS }\end{array}$ & $\mathrm{A}$ & B & $\mathrm{C}$ & $\mathrm{D}$ & $E$ & $\mathrm{~F}$ & $\mathrm{G}$ & $\mathrm{H}$ & $\mathrm{I}$ \\
\hline$\%$ de inclinação & $+0,13$ & $+0,17$ & $-0,26$ & $-0,24$ & $-0,49$ & $-0,58$ & $-0,36$ & $-0,22$ & $-0,6$ \\
\hline$\%$ de biodetrito & 0,09 & 1,16 & 0 & 0,01 & 0,27 & 1,91 & 1,96 & 1,48 & 0,38 \\
\hline$\%$ de areia grossa & 1,93 & 1,15 & 1,39 & 0,75 & 3,06 & 1,31 & 2,14 & 1,69 & 1,32 \\
\hline$\%$ de areia média & 7,10 & 2,16 & 6,53 & 2,85 & 11,32 & 5,91 & 6,73 & 11,99 & 7,65 \\
\hline$\%$ de areia fina & 68,7 & 54,6 & 56,1 & 75,2 & 58,9 & 63,2 & 61,5 & 60,3 & 59,1 \\
\hline$\%$ de areia muito fina & 19,37 & 33,78 & 31,39 & 19,40 & 23,60 & 21,86 & 26,36 & 7,58 & 29,24 \\
\hline$\%$ de silte + argila & 2,86 & 2,76 & 6,11 & 1,86 & 2,80 & 1,52 & 1,27 & 0,87 & 1,92 \\
\hline$\%$ de matéria orgãnica & 1,4 & 2,1 & 1,9 & 2,4 & 2,8 & 2,4 & 1,4 & 2,0 & 2,1 \\
\hline$\%$ de carbonatos & 0,3 & 0,4 & 0,4 & 0,5 & 0,6 & 0,6 & 0,4 & 0,4 & 0,4 \\
\hline Temperatura do ar $\left({ }^{\circ} \mathrm{C}\right)$ & 24,0 & 24,0 & 22,5 & 23,0 & 22,0 & 19,0 & 19,0 & 20,0 & 19,5 \\
\hline Temperatura da água $\left({ }^{\circ} \mathrm{C}\right)$ & 25,5 & 25,5 & 25,0 & 23,5 & 23,5 & 20,0 & 21,0 & 22,0 & 21,5 \\
\hline Temperatura do sedimento $\left({ }^{\circ} \mathrm{C}\right)$ & 24,0 & 23,0 & 22,0 & 22,0 & 20,0 & 21,0 & 20,5 & 21,5 & 21,5 \\
\hline Salinidade (S) & 29 & 32 & 30 & 32 & 18 & 31 & 30 & 31 & 26 \\
\hline $\mathrm{Ph}$ & 7,5 & 7,8 & 7,4 & 7,6 & 7,6 & 7,9 & 7,9 & 7,1 & 7,6 \\
\hline
\end{tabular}


Topometria: Os resultados obtidos mostram que situações de aclividade concentram-se nas estações mais externas (linhas A e B) enquanto a região central (linhas $\mathrm{C} \mathrm{a} \mathrm{H}$ ) caracteriza-se por apresentar moderada declividade (mais acentuada em F). A estação mais interna (linha I) apresenta-se como um plano (Fig. 2).

\section{Parâmetros físico-químicos}

pH e salinidade: $\mathrm{O} \mathrm{pH}$ foi relativamente constante ao longo das estações $(7,1-7,9)$ não exibindo um padrão de variação. No plano vertical os valores tendem a aumentar da superfície para o fundo, na maioria das estações. Os valores de salinidade distribuíram-se de forma irregular no plano horizontal, mantendose entre 29 e $32 \mathrm{~S}$. Valores mais baixos foram registrados nas estações E (18 S) e I (26 S). No plano vertical a salinidade acompanha o $\mathrm{pH}$, exibindo um ligeiro aumento da superfície para o fundo.

Temperatura: As temperaturas do sedimento apresentaram pequena variação ao longo do plano horizontal com valores mais elevados nas estações A e B. No plano vertical as maiores flutuações ocorreram no primeiro estrato. Excetuando a estação F, a temperatura da água de superfície foi sempre superior ao do primeiro estrato do sedimento $(0-5 \mathrm{~cm})$. A temperatura do ar variou entre 19 e $24{ }^{\circ} \mathrm{C}$.

Parâmetros sedimentológicos Teor de umidade e de porosidade: Os teores de umidade e porosidade variaram pouco no plano horizontal - 18,6 a $37,2 \%$ e 23 a $40 \%$, respectivamente, sendo ligeiramente mais elevados nas estações centrais $\left(\begin{array}{lllll}C & \text { a } & \text { G } & \text { e }\end{array}\right.$ menores nas estações mais externas (A e B). A maior parte dos testemunhos analisados apresentou valores praticamente uniformes nos estratos superiores, exibindo um decréscimo mais ou menos acentuado a partir dos dez primeiros centímetros.

Teor de matéria orgânica e carbonatos: Os teores de matéria orgânica e carbonatos, apesar da pequena variação, são levemente mais elevados nas estações centrais (D a F), onde também foi maior o percentual de silte e argila $(1,52-2,80 \%)$. De forma geral os teores de matéria orgânica diminuem da superfície para o fundo, a exceção das estações $\mathrm{D}$ e $\mathrm{H}$ que apresentaram seus maiores valores, nos estratos $30-35 \mathrm{~cm}$ e $20-25 \mathrm{~cm}$, respectivamente. Os teores de carbonato apresentaram comportamento inverso alcançando seus maiores teores em estratos mais profundos, o que parece refletir a maior participação de calcáreo biodetrítico.

Análise granulométrica: De forma geral o sedimento de superfície $(0-5 \mathrm{~cm})$ do Saco do Limoeiro pode ser caracterizado por apresentar predomínio das frações de areia fina e muito fina $(83,86$ - 95,24\%). É composto por areias moderadamente a bem selecionadas, aproximadamente simétricas a negativas, leptocúrtica, com baixos teores de silte + argila (0,88 - 7,60\%). A coloração é variável entre cinza (A,B,C,H e I) a castanho claro e escuro (D a G). Predominam grãos angulosos a subangulosos. 


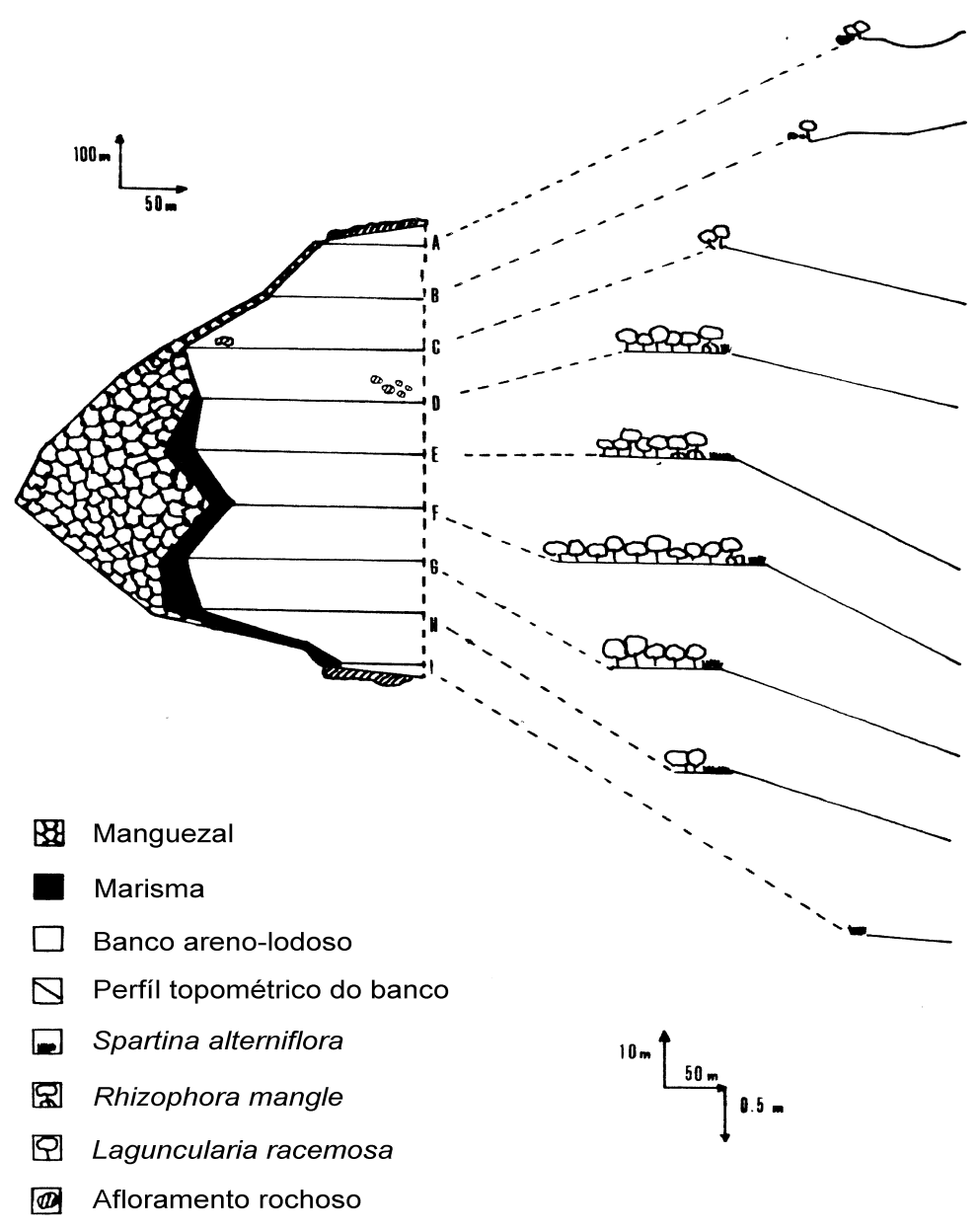

Figura 2. Croqui dos perfis topográficos realizados na área de estudo. Estão representadas as formações de manguezal e marisma, com a respectiva distribuição de seus elementos.

No plano horizontal a participação de areia muito fina é maior nas estações centrais ( $\mathrm{C}$ a F), decrescendo em direção aos extremos. Predomina a fração areia fina em A, B e G e fina a média em $\mathrm{H}$ e I (Tab. II), enquanto no plano vertical as estações A e B apresentam nítida concentração de areia fina e muito fina no estrato superior $(0-5 \mathrm{~cm})$ e de areia média e grossa nos inferiores $(5-35 \mathrm{~cm})$. Nas estações centrais (C - G) os testemunhos são caracterizados pelo predomínio de areia fina e muito fina em $\mathrm{C}, \mathrm{D}, \mathrm{E}$ e $\mathrm{F}$ e fina em $\mathrm{G}$, com distribuição uniforme até $20 \mathrm{~cm}$ de profundidade (Tab. II). Este limite é marcado por um depósito de valvas, com espessura aproximada de $7 \mathrm{~cm}$. Valvas inteiras e fragmentos das espécies locais de bivalves e gastrópodos são os componentes mais comuns, sendo também encontradas valvas de espécies provenientes de praias arenosas próximas e dos setores internos e médios da plataforma (até 80 m) (Tab. III). Abaixo deste estrato predominam areias finas moderadamente a bem selecionadas. As estações H e I apresentam testemunhos uniformes com predomínio de areia fina a média nos 20 primeiros centímetros e média até 40 cm (Tab. II), onde é encontrado um novo depósito de valvas com espessura aproximada de $13 \mathrm{~cm}$ e composição semelhante ao anterior. Ao longo de todos os testemunhos, as valvas do bivalve Anomalocardia brasiliana, em diferentes níveis de retrabalhamento, constituíram-se no material disperso mais abundante. 
Tabela II. Parâmetros estatísticos de Folk \& Ward por estrato e estação.

\begin{tabular}{|c|c|c|c|c|}
\hline$\oplus$ & Diâmetro médio & Grau de seleção & Assimetria & Curtose \\
\hline$\overline{\mathrm{A} 1}$ & 2,67 & moderadamente selecionado & negativa & leptocúrtica \\
\hline A2 & 2,20 & pobremente selecionado & positiva & muito platicúrtica \\
\hline A3 & 1,96 & pobremente selecionado & muito positiva & platicúrtica \\
\hline A4 & 1,91 & pobremente selecionado & muito positiva & platicúrtica \\
\hline A5 & 1,85 & pobremente selecionado & muito positiva & platicúrtica \\
\hline A6 & 1,77 & pobremente selecionado & muito positiva & platicúrtica \\
\hline B1 & 2,93 & bem selecionado & Aproximadamente simétrica & leptocúrtica \\
\hline B2 & 2,30 & pobremente selecionado & muito negativa & leptocúrtica \\
\hline B3 & 2,20 & pobremente selecionado & muito positiva & muito platicúrtica \\
\hline B4 & 1,85 & pobremente selecionado & muito positiva & platicúrtica \\
\hline B5 & 1,96 & pobremente selecionado & muito positiva & platicúrtica \\
\hline B6 & 1,91 & pobremente selecionado & muito positiva & platicúrtica \\
\hline B7 & 1,78 & pobremente selecionado & muito positiva & platicúrtica \\
\hline $\mathrm{C} 1$ & 2,84 & moderadamente selecionado & Aproximadamente simétrica & muito leptocúrtica \\
\hline $\mathrm{C} 2$ & 2,84 & bem selecionado & Aproximadamente simétrica & leptocúrtica \\
\hline $\mathrm{C} 3$ & 2,75 & moderadamente selecionado & Aproximadamente simétrica & muito leptocúrtica \\
\hline $\mathrm{C} 4$ & 2,73 & moderadamente selecionado & Aproximadamente simétrica & leptocúrtica \\
\hline $\mathrm{C} 5$ & 2,76 & moderadamente selecionado & Aproximadamente simétrica & leptocúrtica \\
\hline C6 & 2,65 & moderadamente selecionado & negativa & leptocúrtica \\
\hline C7 & 2,60 & moderadamente selecionado & negativa & leptocúrtica \\
\hline $\mathrm{C} 8$ & 2,61 & moderadamente selecionado & negativa & leptocúrtica \\
\hline D1 & 3,25 & bem selecionado & Aproximadamente simétrica & leptocúrtica \\
\hline D2 & 3,12 & bem selecionado & negativa & leptocúrtica \\
\hline D3 & 3,34 & moderadamente selecionado & muito negativa & muito leptocúrtica \\
\hline D4 & 3,23 & moderadamente selecionado & negativa & leptocúrtica \\
\hline D5 & 3,24 & moderadamente selecionado & Aproximadamente simétrica & muito leptocúrtica \\
\hline D6 & 2,79 & moderadamente selecionado & Aproximadamente simétrica & muito leptocúrtica \\
\hline D7 & 2,71 & moderadamente selecionado & negativa & muito leptocúrtica \\
\hline D8 & 2,66 & moderadamente selecionado & negativa & leptocúrtica \\
\hline E1 & 3,27 & moderadamente selecionado & Aproximadamente simétrica & leptocúrtica \\
\hline E2 & 3,15 & moderadamente selecionado & negativa & leptocúrtica \\
\hline E3 & 3,20 & moderadamente selecionado & negativa & leptocúrtica \\
\hline E4 & 2,80 & moderadamente selecionado & negativa & leptocúrtica \\
\hline E5 & 2,73 & moderadamente selecionado & negativa & leptocúrtica \\
\hline E6 & 2,72 & moderadamente selecionado & muito negativa & muito leptocúrtica \\
\hline E7 & 2,62 & moderadamente selecionado & muito negativa & leptocúrtica \\
\hline E8 & 2,62 & moderadamente selecionado & muito negativa & leptocúrtica \\
\hline F1 & 2,75 & bem selecionado & negativa & leptocúrtica \\
\hline $\mathrm{F} 2$ & 2,74 & moderadamente selecionado & negativa & leptocúrtica \\
\hline F3 & 2,71 & bem selecionado & negativa & leptocúrtica \\
\hline $\mathrm{F} 4$ & 2,69 & moderadamente selecionado & negativa & muito leptocúrtica \\
\hline F5 & 2,67 & moderadamente selecionado & muito negativa & leptocúrtica \\
\hline F6 & 2,61 & moderadamente selecionado & negativa & leptocúrtica \\
\hline F7 & 2,58 & bem selecionado & muito negativa & muito leptocúrtica \\
\hline F8 & 2,51 & bem selecionado & muito negativa & muito leptocúrtica \\
\hline G1 & 2,68 & moderadamente selecionado & negativa & leptocúrtica \\
\hline G2 & 2,67 & moderadamente selecionado & negativa & leptocúrtica \\
\hline G3 & 2,53 & moderadamente selecionado & negativa & muito leptocúrtica \\
\hline G4 & 2,65 & moderadamente selecionado & negativa & leptocúrtica \\
\hline G5 & 2,62 & moderadamente selecionado & muito negativa & muito leptocúrtica \\
\hline G6 & 2,61 & moderadamente selecionado & negativa & leptocúrtica \\
\hline G7 & 2,57 & moderadamente selecionado & negativa & leptocúrtica \\
\hline G8 & 2,42 & moderadamente selecionado & muito negativa & muito leptocúrtica \\
\hline H1 & 2,43 & moderadamente selecionado & negativa & leptocúrtica \\
\hline $\mathrm{H} 2$ & 2,48 & moderadamente selecionado & muito negativa & leptocúrtica \\
\hline $\mathrm{H} 3$ & 2,46 & pobremente selecionado & muito negativa & platicúrtica \\
\hline $\mathrm{H} 4$ & 2,30 & pobremente selecionado & muito negativa & leptocúrtica \\
\hline H5 & 1,72 & pobremente selecionado & muito negativa & mesocúrtica \\
\hline H6 & 1,74 & pobremente selecionado & muito positiva & leptocúrtica \\
\hline $\mathrm{H} 7$ & 1,91 & pobremente selecionado & muito positiva & platicúrtica \\
\hline $\mathrm{H} 8$ & 1,77 & pobremente selecionado & muito positiva & platicúrtica \\
\hline I1 & 2,71 & moderadamente selecionado & negativa & leptocúrtica \\
\hline $\mathrm{I} 2$ & 2,51 & bem selecionado & simétrica & leptocúrtica \\
\hline I3 & 2,56 & moderadamente selecionado & simétrica & leptocúrtica \\
\hline I4 & 2,49 & moderadamente selecionado & negativa & leptocúrtica \\
\hline I5 & 2,34 & moderadamente selecionado & muito negativa & muito leptocúrtica \\
\hline I6 & 1,96 & pobremente selecionado & muito positiva & platicúrtica \\
\hline I7 & 1,77 & pobremente selecionado & muito positiva & platicúrtica \\
\hline
\end{tabular}

Tabela III. Habitat dos Mollusca encontrados nos diferentes estratos dos perfis de sedimento obtidos na planície de maré da parte sul do Saco do Limoeiro (Ilha do Mel - Paraná). 


\section{Classe Bivalvia}

Anomalocardia brasiliana (Gmelin, 1791)*

Codakia costata (Orbigny, 1842)

C. pectinella (Adams, 1852)

Crassostrea rizopharea (Guilding, 1828)

Divaricella quadrisulcata (Orbigny, 1824)

Lucina pectinata (Gmelin, 1791)*

Macoma constricta (Bruguière, 1792)*

Pitar circinatus (Born, 1778)

Trachicardium muricatum (Linnaeus, 1758)

\section{Classe Gastropoda}

Bittium varium (Pfeiffer,1840)*

Bulla striata Bruguière, 1792*

Cerithium atratum (Born, 1778)*

Nassarius vibex (Say, 1822)*

Neritina virginea (Linnaeus, 1758)*

Olivella defiorei Klappenbach, 1964

Pugilina morio (Linnaeus, 1758)*
Águas rasas. Fundos areno-lodosos. Planícies intermareais.

Plataforma interna.

Plataforma interna.

Raízes em manguezais.

Praias arenosas

Águas rasas. Fundos areno-lodosos. Planícies intermareais.

Águas rasas até $10 \mathrm{~m}$. Fundos areno-lodosos. Planícies intermareais.

Plataforma interna e média até $80 \mathrm{~m}$.

Fundos arenosos e lodosos até $32 \mathrm{~m}$.

Planícies arenosas e lodosas intermareais.

Planícies arenosas e lodosas intermareais.

Fundos arenosos e lodosos.

Planícies arenosas e lodosas intermareais.

Planícies arenosas e lodosas intermareais. Marismas.

Plataforma interna e média.

Planícies arenosas e lodosas intermareais. Costões rochosos.

* animais obtidos também vivos na área de estudo

Análise estatística: A análise de agrupamento dos parâmetros analisados ( Fig. 3) mostrou uma similaridade de $65 \%$ entre as estações. A ordenação dos parâmetros (Fig. 4) corroborou a elevada similaridade entre as estações justapostas no plano fatorial. $\mathrm{O}$ eixo $\mathrm{I}$, responsável por $97,4 \%$ da variabilidade total dos dados, foi formado pela participação percentual de areia fina, permitindo considerar a área estudada como relativamente homogênea no que se refere a suas características sedimentológicas e físico-químicas.

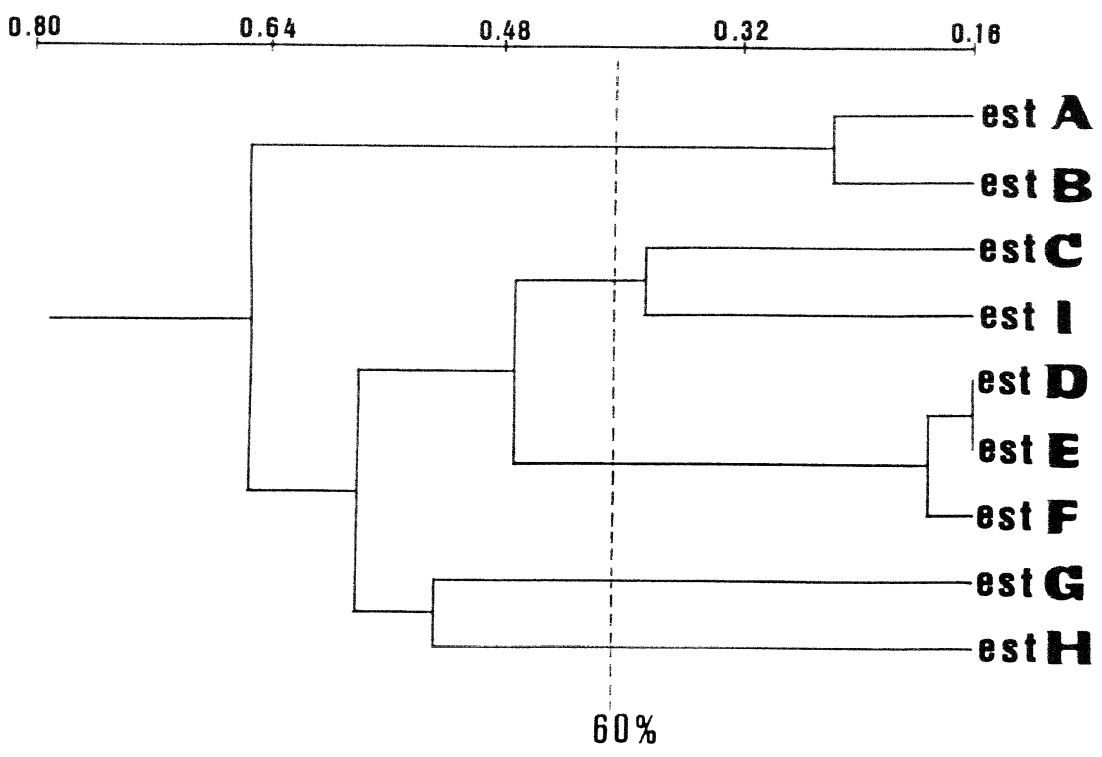

Figura 3. Dendrograma de agrupamento das estações de coleta em função dos parâmetros físico-químicos, a nível de $60 \%$ de similaridade entre as mesmas (coeficiente de Bray-Curtis). 


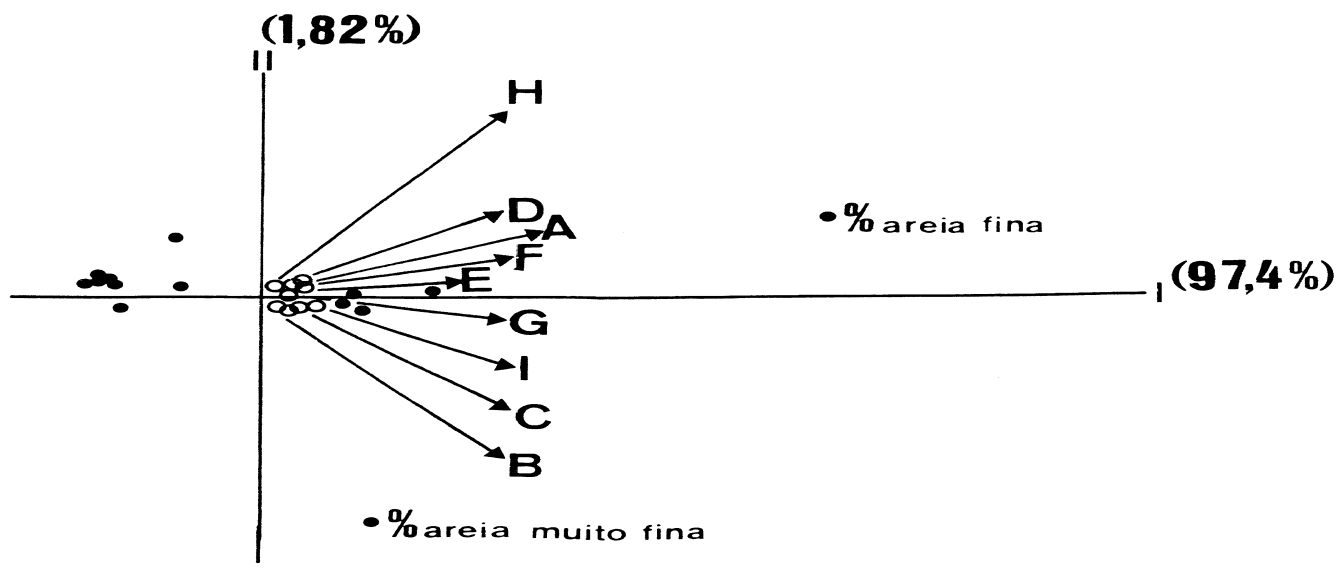

Figura 4. Ordenação dos parâmetros físico-químicos, sedimentológicos e estações de coleta, através da análise de componentes principais.

\section{DISCUSSÃO}

A Ilha do Mel foi formada principalmente durante o Holoceno. Durante as últimas centenas de anos, quando o mar tinha um nível relativo semelhante ao atual, formaram-se os cordões litorâneos aproximadamente paralelos à linha de costa atual. A maior parte da ilha formou-se na fase regressiva após o nível máximo da última transgressão (Angulo, 1992).

A distribuição das situações de aclividade e declividade encontradas no trecho estudado pode estar relacionada à ação das correntes. $\mathrm{O}$ perfil topométrico realizado sugere que no trecho estudado, localizado na parte sul do Saco do Limoeiro, entre dois afloramentos rochosos, existe uma influência maior das correntes de maré vazante. $\mathrm{O}$ afloramento, situado a $37 \mathrm{~m}$ da linha A (mais externa), pode estar funcionando como um anteparo para a deposição do material retirado dos pontos mais centrais do banco (linhas D - H). A exposição do sistema radicular do manguezal entre as linhas $\mathrm{D}$ e $\mathrm{H}$, alcançando até $35 \mathrm{~cm}$ e a mudança abrupta da composição granulométrica nos testemunhos sedimentares obtidos nas linhas A, B e C, com nítida concentração de areia fina a muito fina na parte superior, parecem corroborar esta hipótese.

Durante as passagens de frentes frias os ciclos de maré são mais intensos, uma vez que os ventos provenientes dos quadrantes $\mathrm{S}$ - SE aprisionam a água, fazendo com que aumente o volume de água retido no sistema, por um tempo superior ao dos ciclos normais de maré. Cessados os efeitos deste evento atmosférico, a maior intensidade do fluxo de maré vazante acelera o poder erosivo no fundo da enseada e deposita sedimento contra o anteparo rochoso, alem de promover intensa remobilização dos sedimentos de superfície, provocando mortalidade massiva de algumas especies da macrofauna de sub-superficie.

O tamanho do grão, sua forma, grau de selecionamento, firmeza de empacotamento e estratificação vertical são alguns dos fatores que controlam as dimensões e a forma dos espaços intersticiais e, consequentemente, o teor de umidade e a porosidade (Berner, 1971). Se sedimentos mais finos, que retêm mais água, estão depositados sobre sedimentos mais grosseiros, uma camada superior úmida poderá se manter sobre uma camada mais seca, com conseqüências na distribuição vertical dos organismos, uma vez que pode gerar gradientes químicos verticais acentuados, com a camada redutora desenvolvendo-se logo abaixo da superfície como resposta a mudanças não só no teor de umidade mas também na porosidade, como pode ser observado nas estações A e B. De forma geral a porosidade diminui com o aumento do diâmetro dos grãos, situando-se em torno de $40 \%$ para diâmetros próximos a 0,1 $\mathrm{mm}$ (areia muito fina) e aumentando quando existe uma maior participação de finos. A porosidade foi ligeiramente maior na superfície 
que no fundo. As pequenas diferenças observadas ao longo da maior parte dos testemunhos estão provavelmente relacionadas não só com a pequena participação de finos mas, provavelmente, com a composição destes. Variações nos valores observados podem estar relacionadas a presença de organismos filtradores ou detritívoros, como o tanaidáceo Kalliapseudes schubarti que, através de seus mecanismos de movimentação, alimentação e respiração, podem modificar profundamente as características sedimentológicas e geoquímicas dos sedimentos, afetando, por extensão, os próprios processos de ciclagem e transferência de matéria e energia na interface sedimentoágua (Rhoads \& Young, 1971).

De forma geral o teor de matéria orgânica diminuiu horizontalmente da porção central para os extremos do banco, e dentro do perfil da superfície para o fundo. Entretanto a presença de macroalgas, como por exemplo a rodófita Acanthophora spicifera, abundante na parte central do banco, pode ser responsável por diferenças significativas nos teores de matéria orgânica sobre o sedimento. Características de sua arquitetura permitem que funcione como verdadeira armadilha para a matéria orgânica que chega a área, proveniente da "lavagem" terrígena (restinga, manguezal e marisma) maior fonte, ou aporte marinho (plâncton, bentos e pradaria da angiosperma Halodule wrightii). Esta matéria orgânica está, a princípio, disponível para ser rapidamente incorporada pela epifauna e infauna de subsuperfície, diminuindo a percentagem de carbono que poderia ser depositada no sedimento como carbono detrital, o que pode justificar os baixos teores de matéria orgânica encontrados na área.

Quando a fração calcárea de um sedimento é produzida no mesmo ambiente no qual é depositada, seus aspectos físicos mais importantes como a fragmentação, a cor e/ou brilho e o arredondamento refletem, frequentemente, a história física da área na qual se encontram, diferenciando-se da fração inorgânica que a acompanha, a qual pode ter obtido suas características texturais ao longo dos processos de erosão, transporte e sedimentação, ou seja, sem uma relação direta com o ambiente no qual foram encontradas. A produção de fragmentos orgânicos contidos na matriz sedimentar depende basicamente do rompimento esqueletal. Os mecanismos reconhecidos como mais efetivos para o processo de redução das conchas ou esqueletos a partículas menores são de dois tipos: físicos e biológicos, ou ainda, uma combinação de ambos. As condições físicas do trecho estudado consideradas conjuntamente com as características texturais e a análise do material disperso nos testemunhos sugerem que o mecanismo predominante é o biológico, com as partículas calcáreas de tamanho areia originando-se na própria área de deposição. Entre os organismos envolvidos no processo de fragmentação de valvas estão o porífero Cliona celata, os moluscos Nassarius vibex e Thais haemastoma floridana (Gastropoda) e Martesia striata (Bivalvia), além dos poliquetas espionídeos Polydora socialis e P. websteri. À exceção dos gastrópodos que são predadores, os demais organismos agem perfurando as valvas de indivíduos vivos ou mortos, provocando o enfraquecimento e, conseqüentemente, a fragmentação das mesmas.

$\mathrm{O}$ arredondamento dos grãos minerais e do material calcáreo é uma das características mais empregadas para determinar o grau de rolamento sofrido pelas partículas que compõem o sedimento, assim como o tipo de transporte e o ambiente no qual foram produzidas. Assim, o aspecto muito pouco rolado das partículas calcáreas e a presença de grãos minerais angulosos a subangulosos sugerem um transporte de sedimentos a curta escala nesta área.

A obtenção de um testemunho com $2,5 \mathrm{~m}$ de profundidade $\left(\mathrm{Dr}^{\mathrm{a}}\right.$ Florence Martin - Universitè Paris VII, dados não publicados) mostrou diferentes faixas de deposição de valvas semelhantes às observadas nos testemunhos até $40 \mathrm{~cm}$, exibindo o predomínio de $A$. brasiliana e a presença de espécies locais atuais. Isto sugere que este ambiente tenha apresentado, no passado, uma dinâmica muito semelhante à atual. A presença eventual de espécies características de ambientes com outro tipo de dinâmica pode estar relacionada a passagens 
episódicas de frentes frias, quando ventos provenientes do quadrante sul provocam um aumento na velocidade das correntes e, consequentemente aumentam sua capacidade de transporte podendo trazer material originalmente encontrado na plataforma ou em praias arenosas adjacentes.

\section{AGRADECIMENTOS}

Ao laboratório de Geologia costeira do CEMUFPr pelas facilidades na condução das análises. A. Campos, M.L. Carvalho e S.T. Disaró auxiliaram nas atividades de campo e a J.M. Lima nas análises granulométricas. A.C. Paranhos $\mathrm{F}^{0}$ auxiliou no uso do LABSE.V02. T.M. Absher identificou os moluscos. M.F.L. Souza revisou o abstract. M. Tessler (USP), P.C.F. Gianinni e R.J. Angulo (UFPr) criticaram o manuscrito. A primeira autora contou com bolsa de doutorado CAPES e a segunda autora com bolsa de iniciação científica CNPq/PIBIC/UFPR.

\section{REFERÊNCIAS BIBLIOGRÁFICAS}

Angulo, R.J. 1992. Geologia da planície costeira do Estado do Paraná. Dissertação de Doutorado. Instituto de Geociências. Universidade de São Paulo. 334 pp

Berner, R.A. 1971. Principles of chemical sedimentology. McGraw-Hill Inc., New York, International Series in the Earth and Planetary Sciences, $240 \mathrm{p}$

Bigarella, J.J. 1978. A Serra do Mar e a porção oriental do estado do Paraná - um problema de segurança nacional., Curitiba, SEPLAN/ADEA. 249p

Brandini, F.P. 1985. Ecological studies in the bay of Paranaguá.I. Horizontal distribution and seasonal dynamics of the phytoplankton.
Bol. Inst. Oceanogr., São Paulo, 33: 139 147

Couto, E.C.G. 1989. Produção, decomposição e composição química de Typha dominguensis Pers. (Typhaceae) no sistema lagunar de Guarapina, Rio de Janeiro., Dissertação de Mestrado, Depto de Geoquímica, UFF, Niterói, 249 p

Couto, E.C.G.; Almeida, M.V.O. \& Lana, P. da C. 1995. Diversidade e distribuição da macroinfauna bêntica do Saco do Limoeiro, Ilha do Mel, Paraná - outono de 1990. Publção esp. Inst. oceanogr., São Paulo, 11: 239 - 247

Davis, J.C. 1986. Statistics and data analysis in Geology. $2^{\text {nd }}$ edition. John Wiley \& Sons, Singapore, $646 \mathrm{p}$

Dean, W.E. 1974. Determination of carbonate and organic matter in calcareous sediments and sedimentary rocks by loss on ignition: comparasion with others methods. J. Sed. Petrol., 44 (2): 242 - 248

Knoppers, B.A.; Brandini, F.P. \& Thamm, C. 1986. Ecological studies in the bay of Paranaguá. III. Some physical and chemical characteristics. Nerítica, Pontal do Sul, 1(3): 79 - 90

Reise, K. 1985. Tidal flat ecology - an experimental approach to species interactions. Springer-Verlag, Berlin, $191 \mathrm{p}$

Rhoads, D.C. \& Young, D.K. 1971. Animalsediment relations in Cape Cod Bay, Massachusetts. II. Reworking by Molpadia oolitica (Holothuroidea). Mar. Biol., 11: 255 - 261

Suguio, K. 1973. Introdução à sedimentologia. Edta Edgard Blucher Ltda, EDUSP, São Paulo, $317 \mathrm{p}$

Woodin, S.A. 1978. Refuges, disturbance, and community structure: a marine soft-bottom example. Ecology, 59: 274 - 284

Received: October 19, 1996; Revised: November 14, 1996; Accepted: May 10, 1996. 